\title{
Prolonged Synaptic Currents and Glutamate Spillover at the Parallel Fiber to Stellate Cell Synapse
}

\author{
Adam G. Carter and Wade G. Regehr \\ Department of Neurobiology, Harvard Medical School, Boston, Massachusetts 02115
}

Although neurons often fire in bursts, most of what is known about glutamate signaling and postsynaptic receptor activation is based on experiments using single stimuli. Here we examine the activation of ionotropic glutamate receptors by bursts at the parallel fiber to stellate cell synapse. We show that brief stimulus trains generate prolonged AMPA receptor (AMPAR)- and NMDA receptor (NMDAR)-mediated EPSCs recorded in wholecell voltage clamp. These EPSCs contrast with the rapid AMPAR-mediated EPSC evoked by a single stimulus. The prolonged AMPAR-mediated EPSC is promoted by high-frequency and high-intensity trains and can persist for hundreds of milliseconds. This EPSC is also increased by L-trans-2,4-PDC, an inhibitor of glutamate transporters, suggesting that these transporters usually limit the synaptic response to trains. These prolonged EPSCs reflect both receptor properties and a longlasting glutamate signal. In addition, several experiments demonstrate that glutamate spillover can contribute to receptor

Neurons often fire in bursts, during which a variety of processes can enhance or decrease the synaptic response. Most studies of short-term synaptic plasticity during repetitive activity have focused on presynaptic processes such as facilitation and depression (Magleby, 1987; Zucker, 1989, 1999). However, the magnitude and extent of the glutamate signal and the properties of postsynaptic receptors can also shape the synaptic response to bursts (Jonas and Spruston, 1994; Clements, 1996; Frerking and Wilson, 1996; Barbour and Hausser, 1997; Kullmann and Asztely, 1998; Bergles et al., 1999).

Previous studies of postsynaptic receptor activation have often focused on the synaptic response evoked by a single stimulus. At most excitatory central synapses, a single stimulus produces a large and brief glutamate transient in the synaptic cleft (Clements et al., 1992; Diamond and Jahr, 1997). This glutamate is rapidly removed from the cleft by diff usion and glutamate transporters. A train of stimuli can produce much more glutamate release than a single stimulus because of presynaptic facilitation and delayed release (Atluri and Regehr, 1996, 1998). The resulting glutamate levels may be sufficiently large to overwhelm clearance mechanisms, allowing an extended glutamate signal and even glutamate spillover to nearby sites. Thus, the nature of the glutamate signal

\footnotetext{
Received Jan. 28, 2000; revised March 17, 2000; accepted March 28, 2000.

This work was supported by National Institutes of Health Grants R01NS32405-01 and MH/NS32405-01 to W.G.R. and a National Science Foundation graduate fellowship to A.G.C. We thank Chinfei Chen, Anatol Kreitzer, Kaspar Vogt, and Matthew Xu-Friedman for comments on this manuscript.

Correspondence should be addressed to Wade G. Regehr, Department of Neurobiology, Harvard Medical School, 220 Longwood Avenue, Boston, MA 02115. E-mail: wade regehr@hms.harvard.edu.

Copyright (C) 2000 Society for Neuroscience $\quad 0270-6474 / 00 / 204423-12 \$ 15.00 / 0$
}

activation. First, imaging stimulus-evoked changes in presynaptic calcium establishes that distinct parallel fiber bands can be activated. Second, activation of parallel fibers that do not directly synapse onto a given stellate cell can evoke indirect AMPAR- and NMDAR-mediated EPSCs in that cell. Third, experiments using the use-dependent NMDAR blocker MK-801 show that these indirect EPSCs reflect glutamate spillover in response to trains. Together, these findings indicate that stimulus trains can generate a sustained and widespread glutamate signal that can in turn evoke large and prolonged EPSCs mediated by ionotropic glutamate receptors. These synaptic properties may have important functional consequences for stellate cell firing.

Key words: granule cell; parallel fiber; stellate cell; cerebelIum; AMPA receptor; NMDA receptor; glutamate; transporter; spillover

produced by a train may be qualitatively very different from that generated by a single stimulus.

The importance of an extended glutamate signal and spillover has been addressed previously in considering the activation of metabotropic glutamate receptors (mGluRs) (Scanziani et al., 1997; Min et al., 1998; Vogt and Nicoll, 1999). A stimulus train can activate presynaptic mGluRs via glutamate spillover to mediate heterosynaptic depression, whereas a single stimulus is usually ineffective. This consequence of repetitive activity reflects in part the properties of mGluRs, which are often located at extrasynaptic sites and have a high affinity for glutamate.

However, the importance of glutamate spillover is less clear for activation of ionotropic glutamate receptors. At most synapses, a single stimulus can effectively activate both AMPA receptors (AMPARs) and NMDA receptors (NMDARs) (Hestrin et al., 1990b; Edmonds et al., 1995). Because the glutamate signal is brief, deactivation kinetics usually define the synaptic responses mediated by these receptors (Hestrin, 1992, 1993; Barbour et al., 1994; Edmonds et al., 1995). Kainate receptors (KARs) can also be activated by a stimulus train but are poorly activated by a single stimulus (Castillo et al., 1997; Vignes and Collingridge, 1997). In some cases, a train may also produce sufficient spillover to activate NMDA receptors at nearby sites (Kullmann et al., 1996). In contrast, AMPA receptors are less sensitive to this spillover because they have a lower glutamate affinity and faster desensitization kinetics (Patneau and Mayer, 1990; Edmonds et al., 1995). Nevertheless, for synapses at which a large amount of glutamate is released into a confined space, as at calyceal and glomerular synapses, a train can produce a sustained elevation of glutamate and prolonged AMPA receptor activation (Rossi et al., 
1995; Otis and Trussell, 1996; Otis et al., 1996; Silver et al., 1996; Kinney et al., 1997; Slater et al., 1997; Overstreet et al., 1999). However, most synapses lack this specialized anatomy, and glutamate spillover is generally not thought to activate AMPA receptors.

Here we study the synaptic response to brief stimulus trains at the parallel fiber to stellate cell synapse in the transverse cerebellar slice of young rats. This preparation allows us to stimulate distinct parallel fiber inputs to a given stellate cell and to record the evoked synaptic response using whole-cell voltage clamp. We find that high-frequency and high-intensity trains yield a large and prolonged EPSC in stellate cells. We show that this EPSC is mediated by both AMPA and NMDA receptors and reflects an extended glutamate signal which itself partly reflects glutamate spillover at this synapse.

\section{MATERIALS AND METHODS}

Transverse cerebellar slices (300- $\mu$ m-thick) were cut from 17- to 21-d-old Sprague Dawley rats, as described previously (Llano et al., 1991; Atluri and Regehr, 1996). Experiments were conducted at either $24 \pm 1$ or $34 \pm$ $1{ }^{\circ} \mathrm{C}$. The control external solution consisted of (in mM): $125 \mathrm{NaCl}, 2.5$ $\mathrm{KCl}, 1.5 \mathrm{CaCl}_{2}, 1 \mathrm{MgCl}_{2}, 26 \mathrm{NaHCO}_{3}, 1.25 \mathrm{NaH}_{2} \mathrm{PO}_{4}, 25$ glucose, and 0.02 bicuculline, bubbled with $95 \% \mathrm{O}_{2} / 5 \% \mathrm{CO}_{2}$. Flow rates at 24 and $34^{\circ} \mathrm{C}$ were $2-3$ and $4-6 \mathrm{ml} / \mathrm{min}$, respectively.

Parallel fibers were stimulated using an extracellular glass microelectrode placed in the molecular layer $\geq 100 \mu \mathrm{m}$ from the recording electrode. The tip diameter of this stimulus electrode was typically $10 \mu \mathrm{m}$, and stimulus intensities ranged from 5 to $40 \mu \mathrm{A}$ with stimulus durations of 0.1-0.5 msec. In some experiments, a second stimulating electrode was placed in the molecular layer tens of micrometers from the first electrode, and two tracts of parallel fibers were independently stimulated.

All recordings were made from stellate cells in the outer two-thirds of the molecular layer of the cerebellar cortex. EPSCs were recorded using whole-cell voltage clamp with an Axopatch 200B amplifier (Axon Instruments, Foster City, CA). These recordings were obtained using 1.8-2.5 $\mathrm{M} \Omega$ glass pipettes containing an internal solution of (in $\mathrm{mm}$ ): $35 \mathrm{CsF}, 100$ $\mathrm{CsCl}, 10$ EGTA, and $10 \mathrm{HEPES}, \mathrm{pH}$ 7.3-7.4. Series resistance (typically $5-10 \mathrm{M} \Omega$ ) and leak current (typically -5 to $-20 \mathrm{pA}$ at $-40 \mathrm{mV}$, and -10 to $-30 \mathrm{pA}$ at $-70 \mathrm{mV}$ ) were monitored continuously, and experiments were rejected if either value worsened. Pipettes were wrapped in parafilm to reduce pipette capacitance, as was also the case for the other recording configurations described below. No series resistance compensation was used. Unless otherwise noted, cells were held at $0 \mathrm{mV}$ between parallel fiber stimulations.

Synaptic charge $\left(\mathrm{EPSC}_{\text {charge }}\right)$ was the integrated synaptic current. For single stimuli, the integration period began immediately after the prespike and extended for $10-50 \mathrm{msec}$. For trains, the integration period began immediately after the last stimulus. Because of the variability of the slow component, the integration time was chosen to match the time course of the current and ranged from 0.5 to $2 \mathrm{sec}$. Errors are expressed as SEM.

Stellate cell firing was monitored using both cell-attached patch and whole-cell current-clamp recordings. Cell-attached patch recordings were obtained using 3-4.5 $\mathrm{M} \Omega$ glass pipettes containing a pipette solution of (in mM): $152.5 \mathrm{NaCl}, 2.5 \mathrm{KCl}, 1.5 \mathrm{CaCl}_{2}, 1 \mathrm{MgCl}_{2}, 10 \mathrm{HEPES}$, and 10 glucose, $\mathrm{pH}$ 7.3-7.4. Whole-cell current-clamp recordings were obtained using 3-4.5 $\mathrm{M} \Omega$ glass pipettes containing an internal solution of (in mM): $130 \mathrm{KMeSO}_{3}, 10 \mathrm{NaCl}, 2 \mathrm{MgCl}_{2}, 0.5$ EGTA, $10 \mathrm{HEPES}, 4$ MgATP, 14 creatine phosphate, and 0.3 GTP, pH 7.3-7.4. Current-clamp recordings were made in fast I-clamp mode on the Axopatch 200B amplifier.

All chemicals were from Sigma (St. Louis, MO) with the exception of MCPG [(RS)- $\alpha$-methyl-3-carboxymethylphenylglycine], CPPG [ $(R S)-\alpha-$ cyclopropyl-4-phosphonophenylglycine], NBQX (2,3-dioxo-6-nitro1,2,3,4-tetrahydrobenzo[f]quinoxaline-7-sulfonamide), D-AP-5 (D(-)2-amino-5-phosphonopentanoic acid), PDC (L-trans-2,4-PDC), CTZ [6-chloro-3,4,-dihydro-3-(2-norbornen-5-yl)-2H-1,2,4-benzothiadiazine7 -sulfonamide -1,1 - dioxide; cyclothiazide], MK-801 [(5R,10S) - (+) -5 methyl-10,11-dihydro-5H-dibezo[a,d]cyclohepten-5,10-imine] (Tocris Cookson, Ballwin, MO), and GYKI 53655 (gift from Eli Lilly \& Co., Indianapolis, IN).

Outputs of the Axopatch 200B were filtered at $5 \mathrm{kHz}$ and digitized with

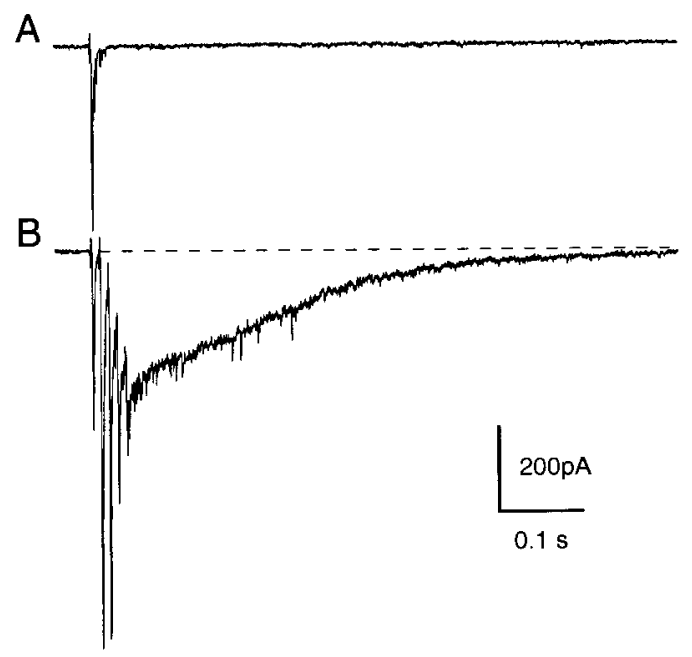

Figure 1. Stellate cell EPSCs evoked by parallel fiber stimulation. Whole-cell voltage-clamp recordings from stellate cells in response to one $(A)$ or five $(B)$ pulses delivered to the parallel fibers at $100 \mathrm{~Hz}$. Recordings were made at $-60 \mathrm{mV}$ in the absence of antagonists. Stimulus artifacts are blanked for clarity, and traces are single trial examples.

a 16 bit digital-to-analog converter (Instrutech, Great Neck, NY), Pulse Control software (Herrington and Bookman, 1995), and an Apple Computers (Cupertino, CA) Macintosh Quadra 650 computer. Analysis was done on- and off-line with Igor Pro software (WaveMetrics, Lake Oswego, OR).

For the experiment shown in Figure 7, parallel fibers were labeled using local application of the membrane-permeant dye Oregon Green 488 BAPTA-1 AM (Molecular Probes, Eugene, OR) in solution, as described previously (Regehr and Tank, 1991; Regehr and Atluri, 1995). The loading time was $20 \mathrm{~min}$, and the imaging was performed $\sim 2 \mathrm{hr}$ later. Two bands of parallel fibers were stimulated using pipettes with tip diameters of $10 \mu \mathrm{m}$, with a stimulus intensity of $5 \mu \mathrm{A}$ and stimulus duration of $0.5 \mathrm{msec}$. Fluorescence was detected using an Olympus Optical (Tokyo, Japan) confocal microscope equipped with an argon laser. Scan time for each image was $\sim 1$ sec.

\section{RESULTS}

Synaptic responses to brief stimulus trains were studied at the granule cell to stellate cell synapse in transverse cerebellar brain slices of young rats. In these slices, granule cell parallel fibers run across the surface of the molecular layer where they contact several types of neurons (Palay and Chan-Palay, 1974). One such target is the stellate cell, a small inhibitory interneuron located in the outer two-thirds of the molecular layer. We stimulated parallel fibers with glass microelectrodes placed in the molecular layer and recorded EPSCs in stellate cells using whole-cell voltage clamp. All experiments were performed in the presence of bicuculline to eliminate synaptic responses mediated by $\mathrm{GABA}_{\mathrm{A}}$ receptors.

\section{Stimulus trains and the prolonged synaptic response}

As shown previously, a single stimulus evoked a fast EPSC in a stellate cell held at $-60 \mathrm{mV}$ (Fig. 1A) (Barbour et al., 1994; Atluri and Regehr, 1998). The fast decay of this EPSC reflects a rapid glutamate signal and AMPAR deactivation (Barbour et al., 1994). In contrast, a brief stimulus train of five pulses at $100 \mathrm{~Hz}$ generated a more complex synaptic response (Fig. 1B). The peak EPSCs of this response increased during the train, reflecting an increase in the probability of release caused by facilitation (Atluri and Regehr, 1998). In addition, the EPSC had a prolonged component that is more difficult to explain. The remainder of the 
paper details experiments aimed to clarify the nature of this prolonged EPSC.

\section{Pharmacology of the prolonged synaptic response}

Previous studies at this synapse have found that synaptic currents evoked by single stimuli are mediated primarily by AMPARs (Barbour et al., 1994; Glitsch and Marty, 1999). However, stellate cells are thought to possess a variety of other glutamate receptors, including mGluRs (Baude et al., 1993), NMDARs (Monyer et al., 1994; Cull-Candy et al., 1998), and KARs (Bahn et al., 1994). A stimulus train may produce a glutamate signal sufficient to activate these receptors, thereby generating the prolonged EPSC. We thus used pharmacology to determine the glutamate receptors responsible for mediating the prolonged EPSC evoked by a stimulus train.

We first used the mGluR antagonists MCPG (group I/II) and CPPG (group II/III) to determine a role for these receptors in mediating the prolonged EPSC. We quantified the effects of these antagonists using the peak synaptic current $\left(\mathrm{EPSC}_{\text {peak }}\right)$ and the synaptic charge $\left(\mathrm{EPSC}_{\text {charge }}\right)$, which is the integrated synaptic current after the last stimulus in a train (see Materials and Methods). We found that application of either MCPG (0.5-1 mM) or CPPG $(30 \mu \mathrm{M})$ had no effect on $\mathrm{EPSC}_{\text {charge }}$ or $\mathrm{EPSC}_{\text {peak }}$ recorded while holding cells at $-40 \mathrm{mV}$ [for $\mathrm{MCPG}, \mathrm{EPSC}_{\text {charge }}$ was $99 \pm 29 \%$ and $\mathrm{EPSC}_{\text {peak }}$ was $95 \pm 7 \%(n=3)$ of control; for $\mathrm{CPPG}, \mathrm{EPSC}_{\text {charge }}$ was $104 \pm 26 \%$ and $\mathrm{EPSC}_{\text {peak }}$ was $92 \pm 5 \%$ $(n=3)$ of control]. Thus, activation of mGluRs does not contribute to the synaptic response evoked by a brief stimulus train at this synapse under our recording conditions.

We next used blockers of different ionotropic glutamate receptors to determine their relative contributions to the synaptic response evoked by a stimulus train. Coapplication of NBQX (10 $\mu \mathrm{M})$ and D-AP-5 $(200 \mu \mathrm{M})$, blockers of non-NMDARs and NMDARs, respectively, eliminated this synaptic response at all holding potentials (data not shown, $n=5$ ). Application of NBQX alone eliminated the peak EPSCs and revealed an outwardly rectified EPSC typical of NMDARs (Fig. $2 A i, B$ ). This EPSC gradually rose during the stimulus train but was usually small or absent after a single stimulus. However, the small size of this EPSC at $-60 \mathrm{mV}$ suggests that it is not responsible for the prolonged EPSC shown in Figure 1. Application of D-AP-5 alone eliminated this outwardly rectified EPSC and revealed a prolonged EPSC at all holding potentials (Fig. 2Aii, B). Thus, we found that both NMDARs and non-NMDARs can contribute to the synaptic response to a stimulus train but that the prolonged EPSC shown in Figure 1 is most likely mediated by non-NMDARs.

The prolonged non-NMDAR-mediated EPSC could be attributable to activation of AMPARs or KARs. Synaptic currents mediated by KARs have a slow time course and can become prominent during stimulus trains, making KARs a good candidate for contributing to the synaptic response (Castillo et al., 1997; Vignes and Collingridge, 1997). We tested for this possibility using GYKI 53655, a selective blocker of AMPARs that does not block KARs. Application of GYKI $53655(30 \mu \mathrm{M})$ eliminated the prolonged non-NMDAR-mediated EPSC recorded while holding cells at $-40 \mathrm{mV}\left(\right.$ EPSC $_{\text {charge }}$ was $6 \pm 2 \%$ and $\mathrm{EPSC}_{\text {peak }}$ was $5 \pm 2 \%$ of control; $n=3$ ) (Fig. $2 C$ ). This finding indicates that this EPSC is mediated solely by activation of AMPARs. This is intriguing, because AMPAR-mediated EPSCs evoked by a single stimulus are very fast at this synapse and these AMPARs rapidly desensitize in the sustained presence of glutamate (Barbour et al., 1994).
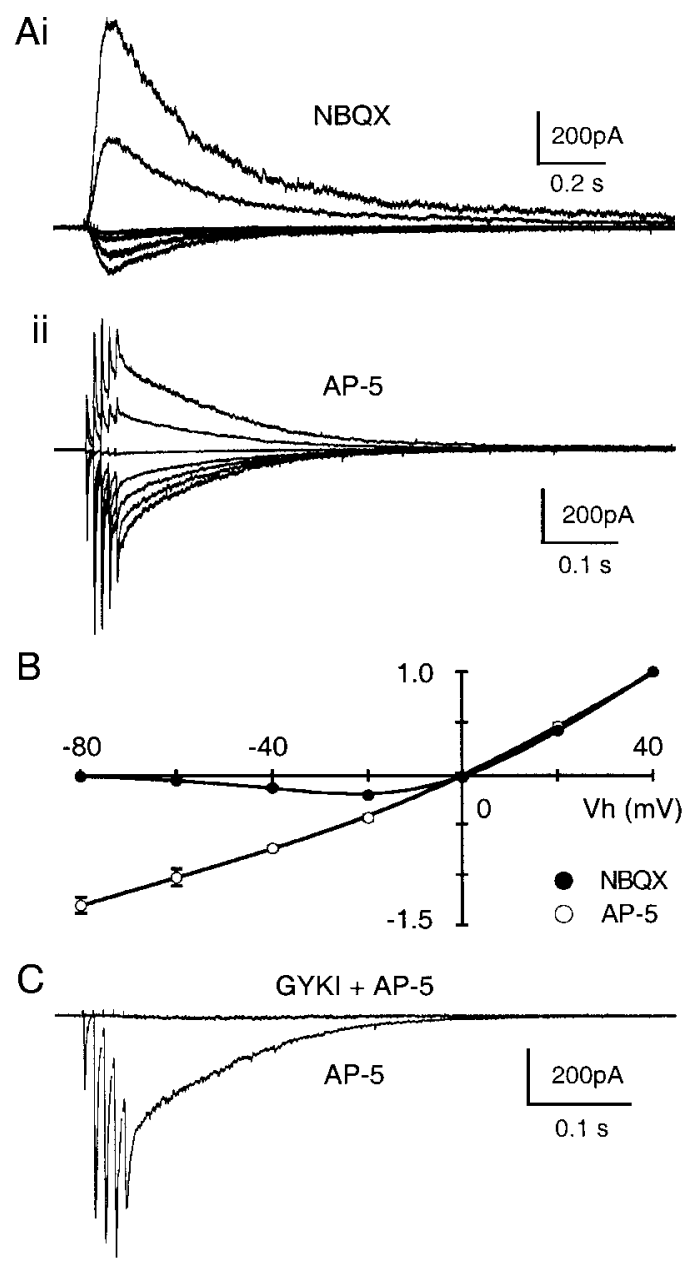

Figure 2. Pharmacology of the EPSCs. A, EPSCs evoked by five pulses at $100 \mathrm{~Hz}$ measured at holding potentials of $-80,-60,-40,-20,0,+20$, and $+40 \mathrm{mV}$. Recordings were made in the presence of either $10 \mu \mathrm{M}$ NBQX $(i)$ or $200 \mu \mathrm{M}$ D-AP-5 (ii). B, Normalized peak EPSCs versus holding potential in the presence of NBQX (closed circles; $n=3$ ) or D-AP-5 (open circles; $n=3$ ). Peak EPSCs evoked at different holding potentials were normalized to those currents evoked at $+40 \mathrm{mV}$. C, EPSCs evoked by five pulses at $100 \mathrm{~Hz}$ measured at $-40 \mathrm{mV}$ while in the presence of either $50 \mu \mathrm{M}$ D-AP-5 or $30 \mu \mathrm{M}$ GYKI 53655 plus $50 \mu \mathrm{M}$ D-AP-5. Recordings in $A-C$ are from different cells, and traces are averages of two to five trials.

\section{Stimulus conditions that generate the prolonged AMPAR-mediated EPSC}

We next sought to clarify the stimulus conditions that generate the prolonged AMPAR-mediated EPSC. As indicated in Figure 1 , when the number of pulses in the train was increased from one to five, the EPSC decayed much more slowly (Fig. 3A). Furthermore, when the frequency of a five pulse train was increased from 10 to $100 \mathrm{~Hz}$, the EPSC was again prolonged (Fig. $3 B$ ). This is shown by a scaled comparison of the two EPSCs after the last stimulus in each of the trains (Fig. 3B, bottom). Moreover, when the intensity of a five pulse train was increased 10 -fold, from 3 to $30 \mu \mathrm{A}$, the EPSC again decayed more slowly (Fig. $3 C$ ). Thus, the prolonged AMPAR-mediated EPSC is accentuated by trains of high-frequency and high-intensity stimuli, and we therefore used such stimuli throughout the remainder of this study. 

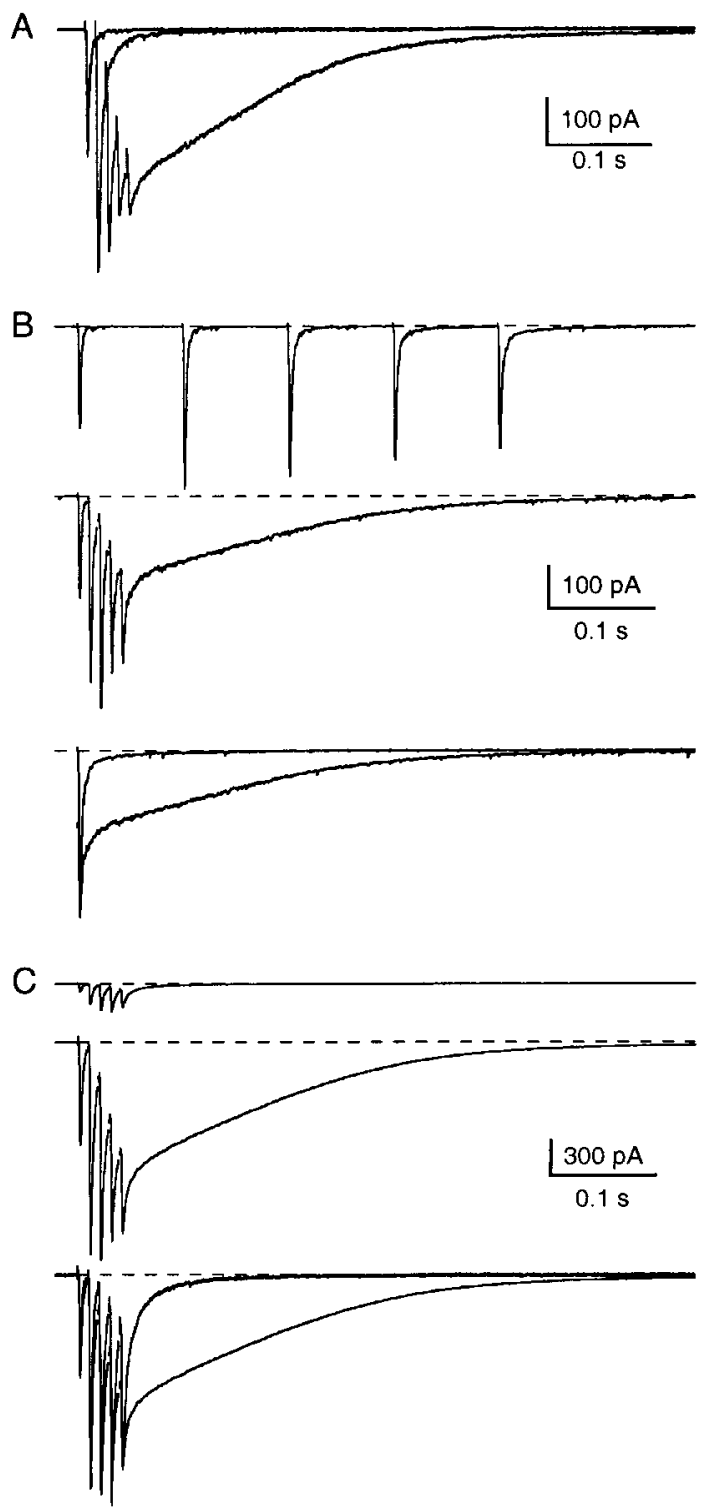

Figure 3. Stimulus conditions that elicit the prolonged AMPARmediated EPSC. $A$, EPSCs evoked by one, two, and five pulses at $100 \mathrm{~Hz}$. $B$, EPSCs evoked by five pulses at 10 (top) or 100 (middle) $\mathrm{Hz}$, and a scaled comparison of the time course of decay after the fifth stimulus (bottom). C, EPSCs evoked by five pulses at $100 \mathrm{~Hz}$ and either 3 (top) or 30 (middle) $\mu \mathrm{A}$, and a comparison of the responses scaled to the last peak (bottom). Recordings were made at $-40 \mathrm{mV}$, and $50 \mu \mathrm{M}$ D-AP-5 was present for all experiments. Recordings in $A-C$ are from different cells, and traces are averages of $10-40$ trials.

\section{The prolonged AMPAR-mediated EPSC is not attributable to poor voltage clamp}

Inadequate voltage clamp could contribute to the slow, nonexponential decay of the prolonged EPSC (Spruston et al., 1993). We performed two types of experiments to show that this was not the case. First, we conducted a voltage jump experiment (Hestrin et al., 1990a; Pearce, 1993; Barbour et al., 1994) in which the cell was stimulated while held at $0 \mathrm{mV}$, and the holding potential was stepped to $-40 \mathrm{mV}$ at different times after the stimulus train (Fig. $4 \mathrm{Ai}$ ). If the prolonged AMPAR-mediated EPSC reflects poor voltage clamp, there should be a clear difference between these responses and those evoked while the cell was held at $-40 \mathrm{mV}$
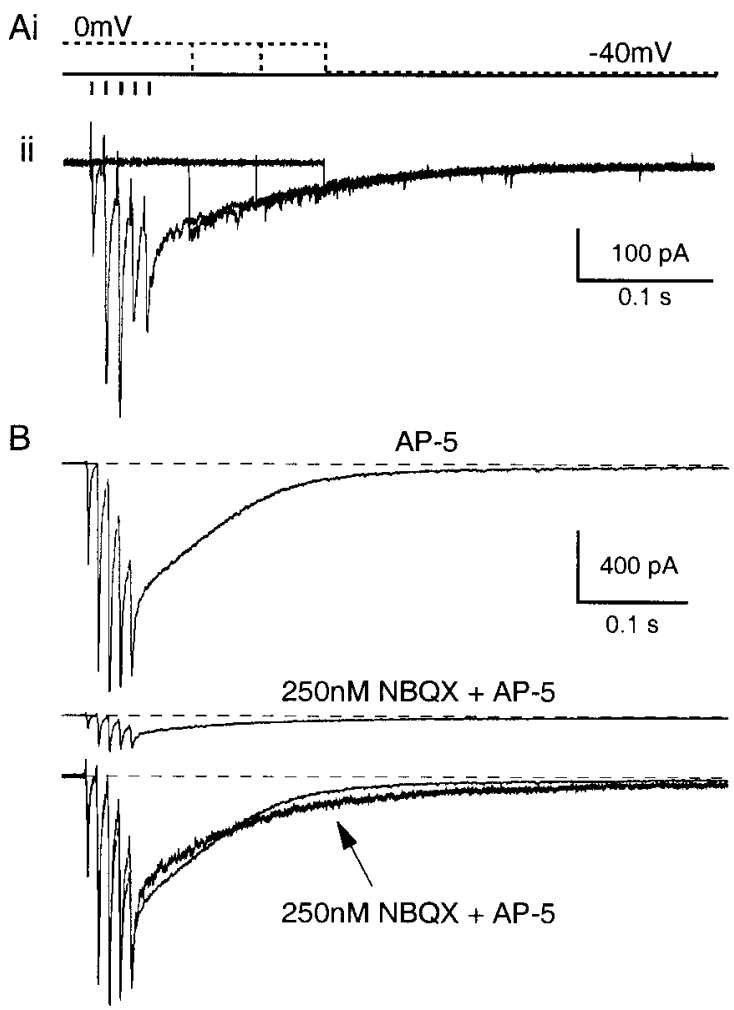

Figure 4. The prolonged AMPAR-mediated EPSC is not a consequence of poor voltage clamp. $A$, EPSCs evoked by five pulses at $100 \mathrm{~Hz}$ measured either at $-40 \mathrm{mV}$ or after stepping from 0 to $-40 \mathrm{mV}$ during the slow component of the EPSC, as shown in the schematic ( $i)$. After the step to $-40 \mathrm{mV}$, the EPSCs are closely aligned (ii). The capacitative current has been subtracted. $B$, EPSCs evoked by five pulses at $100 \mathrm{~Hz}$ measured at $-40 \mathrm{mV}$ while in the presence of either D-AP-5 (top; bottom, thin line) or $250 \mathrm{~nm}$ NBQX plus D-AP-5 (middle; bottom, thick line), and a comparison of the responses scaled to the last peak (bottom). D-AP-5 (50 $\mu \mathrm{M})$ was present for all experiments. Recordings in $A$ and $B$ are from different cells, and traces are averages of 6-40 trials.

throughout. However, the responses closely align after returning to $-40 \mathrm{mV}$, indicating that voltage clamp was adequate (Fig. 4Aii). Similar results were found in all five cells tested. Next, we applied a low concentration of NBQX (250 nM) to decrease the amplitude of the EPSC, which should reduce any effects of poor voltage clamp (Fig. 4B). A scaled comparison of the EPSCs evoked in the presence and absence of low NBQX shows that a prolonged AMPAR-mediated EPSC is found in both conditions, again indicating that voltage clamp was adequate (Fig. 4 B, bottom). Similar results were found in all four cells tested.

\section{Contributions of glutamate transporters and desensitization to the prolonged AMPAR-mediated EPSC}

We next tested the role of glutamate transporters in shaping the prolonged AMPAR-mediated EPSC evoked by trains. A variety of glutamate transporters are present in the molecular layer of the cerebellum (Rothstein et al., 1994; Chaudhry et al., 1995; Lehre et al., 1995). We blocked these transporters with PDC and assessed the effects on AMPAR-mediated EPSCs. PDC $(200 \mu \mathrm{M})$ decreased the EPSC evoked by a single stimulus (EPSC charge $_{\text {was }}$ $58 \pm 13 \%$ and EPSC $_{\text {peak }}$ was $55 \pm 8 \%$ of control; $\left.n=4\right)($ Fig. $5 A$ ). PDC also increased the leak current, despite the presence of $1 \mathrm{~mm}$ external $\mathrm{Mg}^{2+}$ and D-AP-5 to block NMDARs (Fig. 5B, bottom inset). These findings suggest that blocking glutamate transport- 

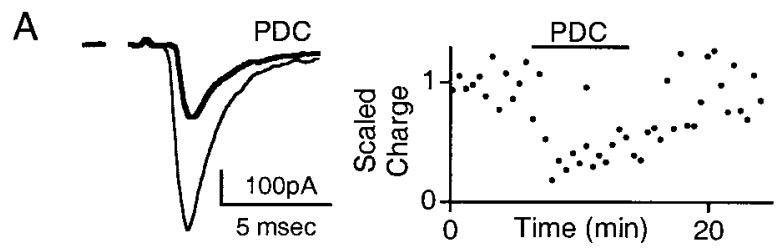

B

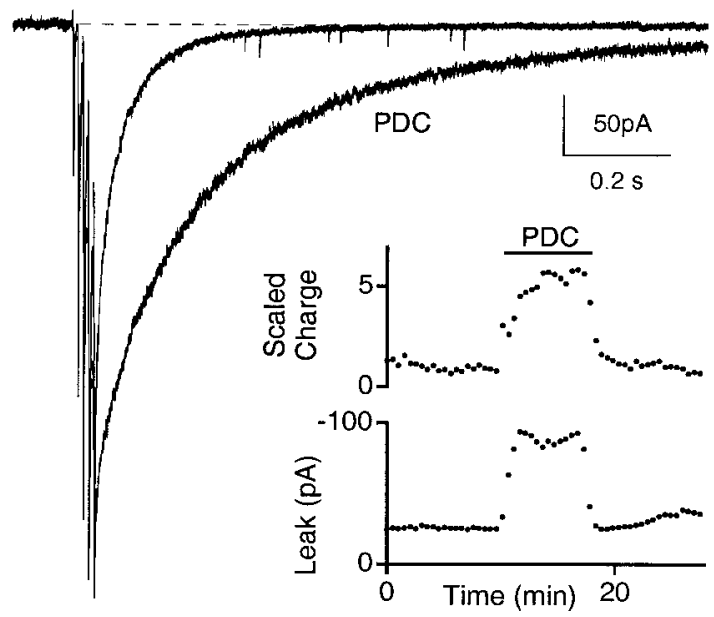

Figure 5. Inhibition of glutamate transporters enhances the prolonged AMPAR-mediated EPSC. EPSCs evoked by one $(A)$ and five $(B)$ pulses at $100 \mathrm{~Hz}$ while in the presence of either D-AP-5 (thin line) or $200 \mu \mathrm{M}$ PDC plus D-AP-5 (thick line). Insets show the effect of PDC on the scaled synaptic charge transfer or leak current. Recordings were made at -40 $\mathrm{mV}$, and $50 \mu \mathrm{M}$ D-AP-5 was present for all experiments. Recordings in $A$ and $B$ are from different cells, and traces are averages of 10 trials.

ers with PDC can increase ambient extracellular glutamate to concentrations that can activate and subsequently desensitize a fraction of AMPARs. However, the negligible effect of PDC on the half-decay time of the EPSC evoked by a single stimulus $\left(t_{1 / 2}\right.$ was $95 \pm 10 \%$ of control; $n=4)$ indicates that glutamate transporters play a limited role in shaping this response, in agreement with previous studies at other synapses (Isaacson and Nicoll, 1993; Sarantis et al., 1993). In contrast, PDC greatly extended the time course of the prolonged AMPAR-mediated EPSC evoked by a stimulus train $\left(\right.$ EPSC $_{\text {charge }}$ was $560 \pm 90 \%$, EPSC $_{\text {peak }}$ was $96 \pm 8 \%$, and $t_{1 / 2}$ was $1020 \pm 120 \%$ of control; $n=4$ ) (Fig. $5 B$ ). These results suggest that the prolonged AMPAR-mediated EPSC evoked by a stimulus train reflects an extended glutamate signal that is controlled by glutamate uptake.

We also tested the role of AMPAR desensitization in shaping

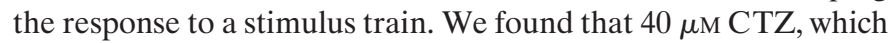
reduces AMPAR desensitization, greatly increased the magnitude and time course of the prolonged AMPAR-mediated EPSC evoked by a stimulus train (EPSC charge $_{\text {was }} 970 \pm 10 \%$ and EPSC $_{\text {peak }}$ was $370 \pm 70 \%$ of control; $n=3$ ) (Fig. $6 A$ ). This dramatic effect of CTZ is consistent with the sustained presence of glutamate after a train and with AMPAR desensitization limiting the synaptic response. However, CTZ can also affect the presynaptic probability of release, AMPAR deactivation, and AMPAR affinity for glutamate (Patneau et al., 1993; Diamond and Jahr, 1995; Dzubay and Jahr, 1999). We found that CTZ had no significant effect on the NMDAR-mediated EPSC evoked by a stimulus train $\left(\mathrm{EPSC}_{\text {charge }}\right.$ was $93 \pm 5 \%$ and $\mathrm{EPSC}_{\text {peak }}$ was also $93 \pm 5 \%$ of control; $n=3$ ) (Fig. $6 B$ ). Because CTZ does not directly affect NMDAR kinetics or glutamate affinity (Trussell et
A
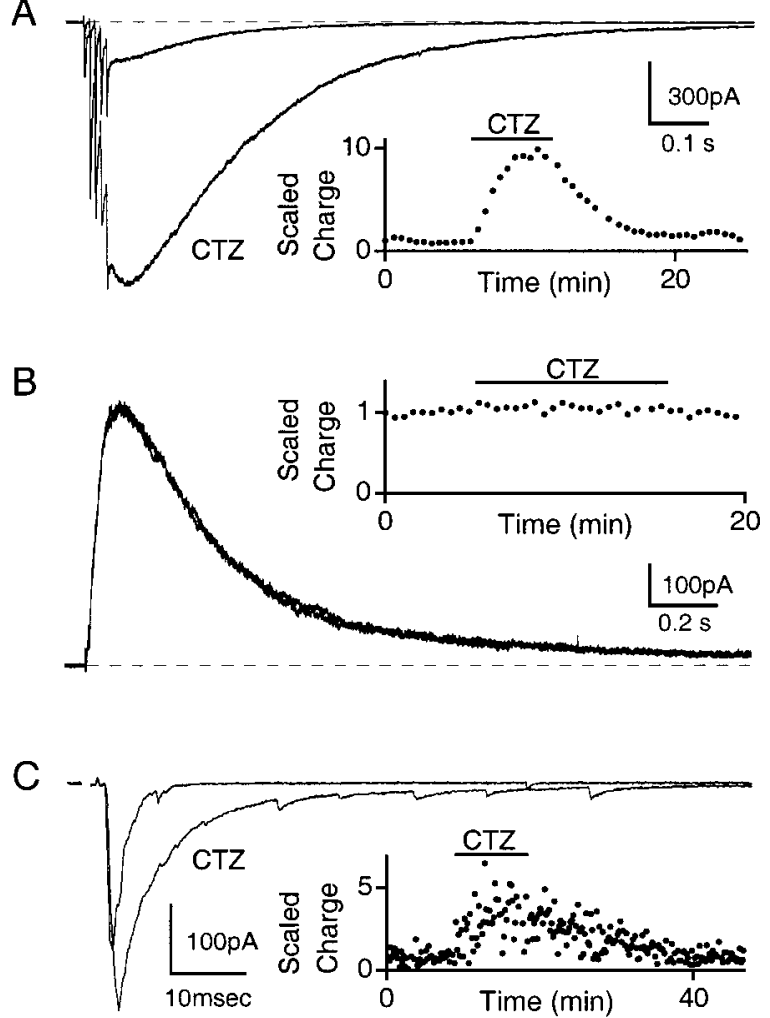

Figure 6. Reduction of AMPAR desensitization enhances the prolonged AMPAR-mediated EPSC. $A$, AMPAR EPSCs evoked by five pulses at $100 \mathrm{~Hz}$ measured at $-40 \mathrm{mV}$ while in the presence of either $50 \mu \mathrm{M}$ D-AP-5 or $40 \mu \mathrm{M}$ CTZ plus $50 \mu \mathrm{M}$ D-AP-5. $B$, NMDAR EPSCs evoked by five pulses at $100 \mathrm{~Hz}$ while in the presence of either $10 \mu \mathrm{M}$ NBQX or 40 $\mu \mathrm{M}$ CTZ plus $10 \mu \mathrm{M}$ NBQX. $C$, AMPAR EPSCs evoked by one pulse measured at $-40 \mathrm{mV}$ while in the presence of either $50 \mu \mathrm{M}$ D-AP-5 or 40 $\mu \mathrm{M} \mathrm{CTZ}$ plus $50 \mu \mathrm{M} \mathrm{D}-\mathrm{AP}-5$. Insets show the effect of CTZ on the scaled synaptic charge transfer. Recordings in $A-C$ are from different cells, and traces are averages of $4-10$ trials.

al., 1993; Mennerick and Zorumski, 1995), we conclude that CTZ does not have significant presynaptic effects under our experimental conditions. We also found that CTZ had a much smaller effect on the AMPAR-mediated EPSC evoked by a single stimulus $\left(\mathrm{EPSC}_{\text {charge }}\right.$ was $380 \pm 50 \%$ and EPSC $_{\text {peak }}$ was $220 \pm 30 \%$ of control; $n=5$ ) (Fig. $6 C$ ) compared with the AMPAR-mediated EPSC evoked by a train. This suggests that, although CTZ affects AMPAR deactivation or glutamate affinity, the effect of CTZ on the synaptic response to a stimulus train primarily reflects the reduction of AMPAR desensitization caused by the prolonged elevation of glutamate.

\section{Imaging activated bands of parallel fiber}

The above findings suggest that trains can produce a sustained elevation of glutamate and raise the possibility that glutamate spillover occurs at this synapse. We next tested for glutamate spillover by taking advantage of the anatomy of the parallel fibers. The goals of these experiments were (1) to determine whether stimulating a pathway that does not directly contact a stellate cell can evoke a synaptic response in that cell, and (2) to show that this response reflects the activation of receptors located at nearby synapses via glutamate spillover. For such experiments, it is necessary to stimulate well defined bands of parallel fibers.

We imaged stimulus-evoked changes in presynaptic calcium to demonstrate our ability to stimulate distinct bands of parallel 

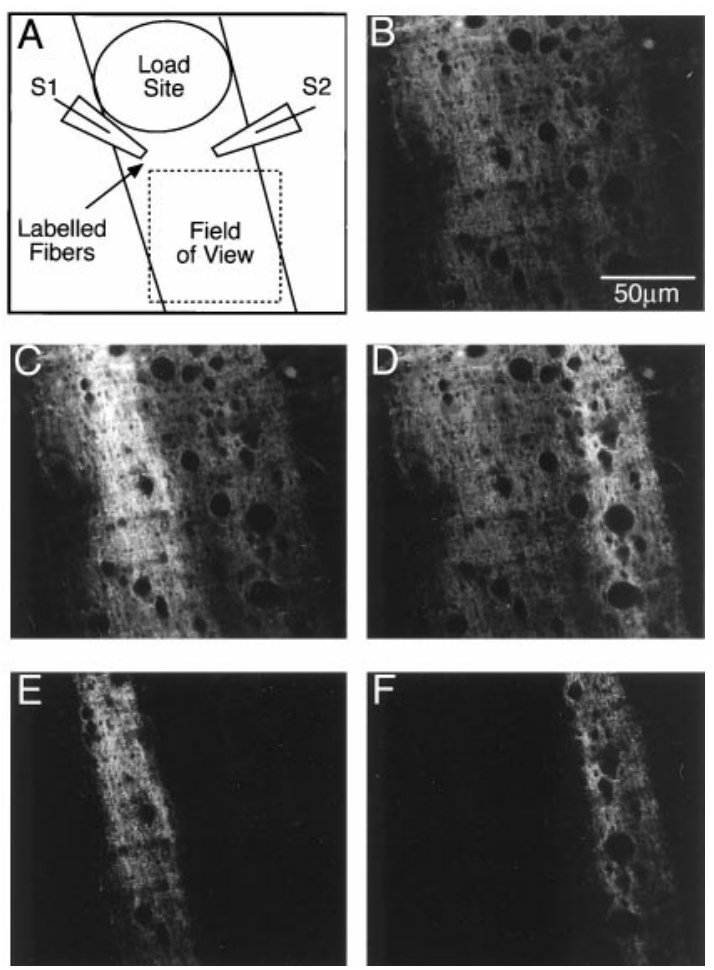

Figure 7. Calcium imaging of parallel fiber bands. A, Schematic illustrating the load site, labeled fibers, location of stimulus electrodes S1 and S2, and field of view in $B-F$. B, Background fluorescence of fibers labeled with Oregon Green 488 BAPTA-1 AM. $C, D$, Fluorescence evoked by 100 pulses at $100 \mathrm{~Hz}$ for electrode $\mathrm{S} 1(C)$ or electrode $\mathrm{S} 2(D) . E, F$, Evoked changes in fluorescence for $\mathrm{S} 1(E)$ and $\mathrm{S} 2(F)$ in which $B$ has been subtracted away from $C$ and $D$, respectively. Traces are single trial examples.

fibers. Parallel fibers were labeled with the calcium-sensitive indicator Oregon Green 488 BAPTA-1 AM (Fig. 7A) (see Materials and Methods). The resulting fluorescence revealed that parallel fibers were labeled, but other cellular structures were not (Fig. 7B). Two stimulus electrodes (S1 and S2) were then placed $\sim 80 \mu \mathrm{m}$ apart in the molecular layer, and two distinct bands of parallel fibers were stimulated $(100$ pulses at $100 \mathrm{~Hz})$. Stimulation of S1 produced an increase in fluorescence in a band of fibers that is apparent in the raw fluorescence (Fig. 7C) and in a trace for which the baseline fluorescence has been subtracted (Fig. 7E). Stimulation with $\mathrm{S} 2$ produced similar results in a separate band of fibers (Fig. 7D, F). These fluorescence changes arise from increases in intracellular $\mathrm{Ca}^{2+}$ levels, and they provide a good measure of the spatial extent of fiber activation. For stimulation with either S1 or S2, the activated bands of fibers were $\sim 40 \mu \mathrm{m}$ in diameter, and these bands did not overlap. Similar stimulation of bands of fibers was observed in all six slices tested.

\section{Indirect EPSCs}

If glutamate spillover occurs at the parallel fiber to stellate cell synapse, then activation of presynaptic terminals that do not directly contact a stellate cell might give rise to a detectable synaptic response. We tested for this possibility by examining EPSCs produced by activation of two parallel fiber pathways, with the goal to identify a direct pathway that makes synaptic contacts onto a particular stellate cell and an indirect pathway that does not (Fig. $8 A$ ). The anatomy of the parallel fibers and our imaging of activated fiber tracts (Fig. 7) indicate that it should be possible

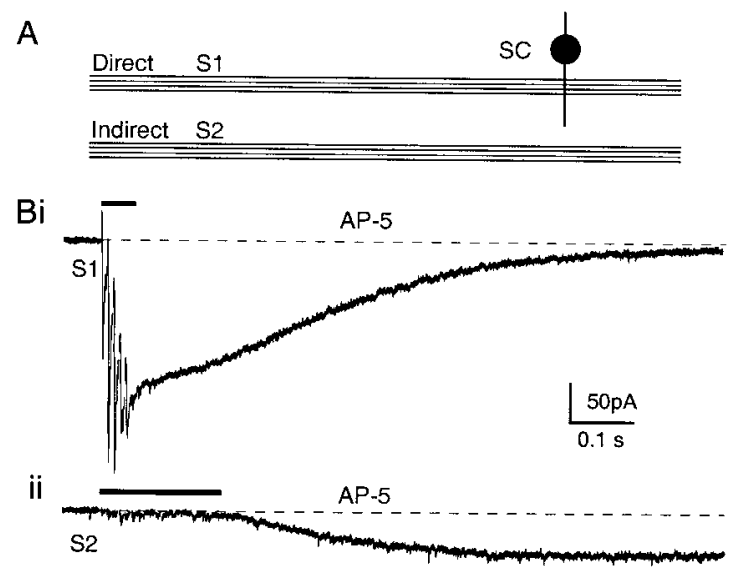

iii

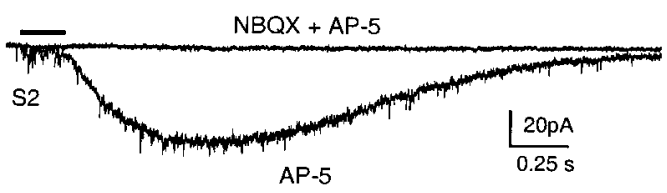

C
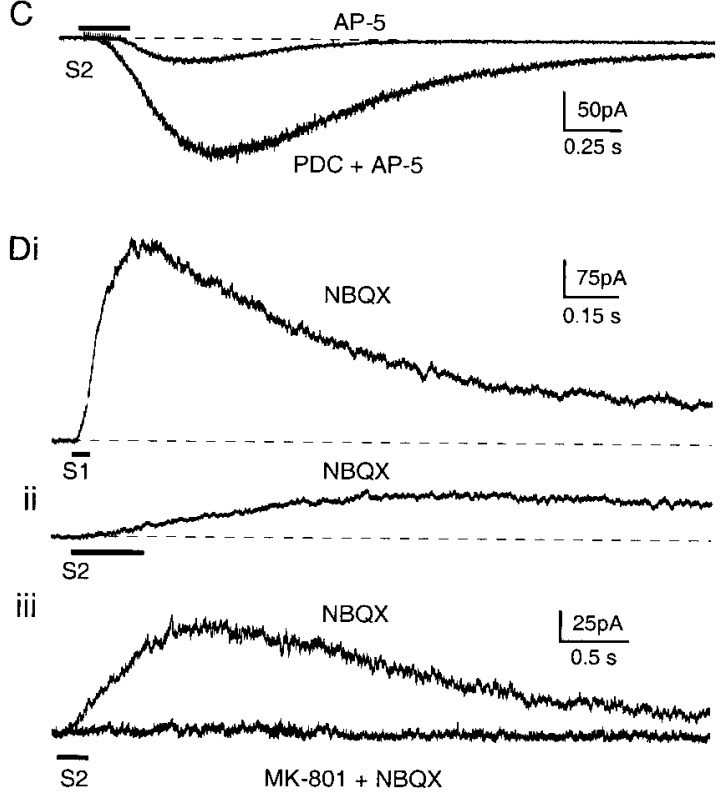

Figure 8. AMPAR- and NMDAR-mediated EPSCs evoked by indirect pathway stimulation. $A$, Schematic illustrating direct (S1) and indirect (S2) pathways. $B$, AMPAR EPSCs evoked by stimulating a direct pathway with five pulses at $100 \mathrm{~Hz}(i)$ or an indirect pathway with 20 pulses at 100 $\mathrm{Hz}$ (ii, iii). Recordings were made at $-40 \mathrm{mV}$, and $50 \mu \mathrm{M}$ D-AP-5 was present. Addition of $10 \mu \mathrm{M}$ NBQX blocked the indirect response (iii). $C$, AMPAR EPSCs evoked by five pulses at $100 \mathrm{~Hz}$ measured at $-40 \mathrm{mV}$ while in the presence of $50 \mu \mathrm{M}$ D-AP- 5 or $200 \mu \mathrm{M}$ PDC plus $50 \mu \mathrm{M}$ D-AP-5. $D$, NMDAR EPSCs evoked by stimulating a direct pathway with five pulses at $100 \mathrm{~Hz}(i)$ or an indirect pathway with 20 pulses at $100 \mathrm{~Hz}(i i$, iii). Recordings were made at $+40 \mathrm{mV}$, and $10 \mu \mathrm{M}$ NBQX was present. Addition of $4 \mu \mathrm{M}$ MK- 801 blocked the indirect response (iii). The duration of stimulation is indicated by the horizontal bars. Scale bar in $B i$ applies to $B i$ and $B i i$; scale bar in $D i$ applies to $D i$ and Dii. Recordings in $B-D$ are from different cells, and traces are averages of four to five trials.

to stimulate these two pathways. In the presence of D-AP-5, stimulation of one pathway (five pulses at $100 \mathrm{~Hz}$ ) yielded fast AMPAR-mediated EPSCs, followed by the prolonged AMPARmediated EPSC (Fig. 8Bi). Based on the presence of the promi- 
nent fast EPSCs, this was identified as a direct pathway. In contrast, stimulation of another pathway (20 pulses at $100 \mathrm{~Hz}$ ) failed to elicit a significant fast response (compare the first 50 msec after the onset of stimulation in Fig. $8 B i, B i i)$ but did produce a small EPSC that gradually developed and slowly decayed (Fig. 8Bii, Biii). Based on the lack of fast EPSCs, this second pathway was identified as an indirect pathway. This indirect response was blocked by $10 \mu \mathrm{M} \mathrm{NBQX}$ (EPSC charge $_{\text {was }} 0.6 \pm$ $0.6 \%$ of control; $n=3$ ) (Fig. 8Biii) and $30 \mu \mathrm{M}$ GYKI 53655 (EPSC $_{\text {charge }}$ was $3.1 \pm 1.5 \%$ of control; $n=5$ ) (data not shown), suggesting that it was mediated by AMPARs. This indirect response was greatly enhanced by $200 \mu \mathrm{M}$ PDC (EPSC $_{\text {charge }}$ was $2100 \pm 700 \%$ of control; $n=4$ ) (Fig. $8 C$ ), indicating that glutamate transporters usually limit this response. This indirect AMPAR-mediated response was also increased by $40 \mu \mathrm{M} \mathrm{CTZ}$ (EPSC $_{\text {charge }}$ was $1050 \pm 80 \%$ of control; $n=3$ ) (data not shown), suggesting that AMPAR desensitization usually limits this response.

We next examined indirect synaptic responses mediated by NMDARs, whose higher glutamate affinity may allow them to better detect glutamate spillover (Patneau and Mayer, 1990; Edmonds et al., 1995). Direct and indirect pathways were first identified based on AMPAR-mediated EPSCs. We then examined the NMDAR-mediated EPSCs in isolation by including NBQX in the external solution (Fig. 8D). Stimulation of the direct pathway (five pulses at $100 \mathrm{~Hz}$ ) to a cell held at $+40 \mathrm{mV}$ yielded an EPSC that began shortly after the first stimulus, peaked tens of milliseconds after the fifth stimulus, and decayed over several hundred milliseconds (Fig. 8Di). Stimulation of the indirect pathway with 20 pulses at $100 \mathrm{~Hz}$ yielded a much slower EPSC that typically began well into the stimulus train, peaked several hundred milliseconds after the last stimulus, and decayed over several seconds (Fig. 8Dii, Diii). This indirect response was blocked by $4 \mu \mathrm{M}$ MK-801, an open-channel blocker of NMDARs $\left(\right.$ EPSC $_{\text {charge }}$ was $-1.7 \pm 2.5 \%$ of control; $n=7$ ) (Fig. 8 Diii). The simplest explanation for these indirect NMDAR- and AMPARmediated EPSCs is that glutamate released at synapses during a stimulus train can spillover and activate ionotropic glutamate receptors on nearby stellate cells.

\section{Indirect NMDAR-mediated EPSC and glutamate spillover}

We next used MK-801 to further examine the contribution of glutamate spillover to synaptic responses evoked by stimulus trains. MK-801 has been a valuable tool in the study of synaptic transmission by virtue of its ability to block only open NMDARs (Huettner and Bean, 1988; Jahr, 1992; Hessler et al., 1993; Rosenmund et al., 1993). We used MK-801 to block NMDARs opened during the synaptic response to indirect pathway stimulation. If this also reduces the response to direct pathway stimulation at the same cell, then the indirect NMDAR-mediated EPSC must reflect glutamate spillover.

In these experiments, two stimulus electrodes were positioned as in Figure $8 A$, such that one evoked an indirect response (Fig. $9 \mathrm{Ai}$ ) and the other a direct response (Fig. 9Aii, larger trace). After obtaining stable recordings for both pathways, we washed $4 \mu \mathrm{M}$ MK-801 into the bath. Between successive stimulation, the cell was held at $-70 \mathrm{mV}$ to avoid NMDAR activation by extracellular glutamate and subsequent block by MK-801. The indirect pathway was then stimulated once every $30 \mathrm{sec}$ for $5 \mathrm{~min}$ (Fig. 9Aiii). During this time, the indirect response progressively decreased (data not shown). We then tested the response to stimulation of
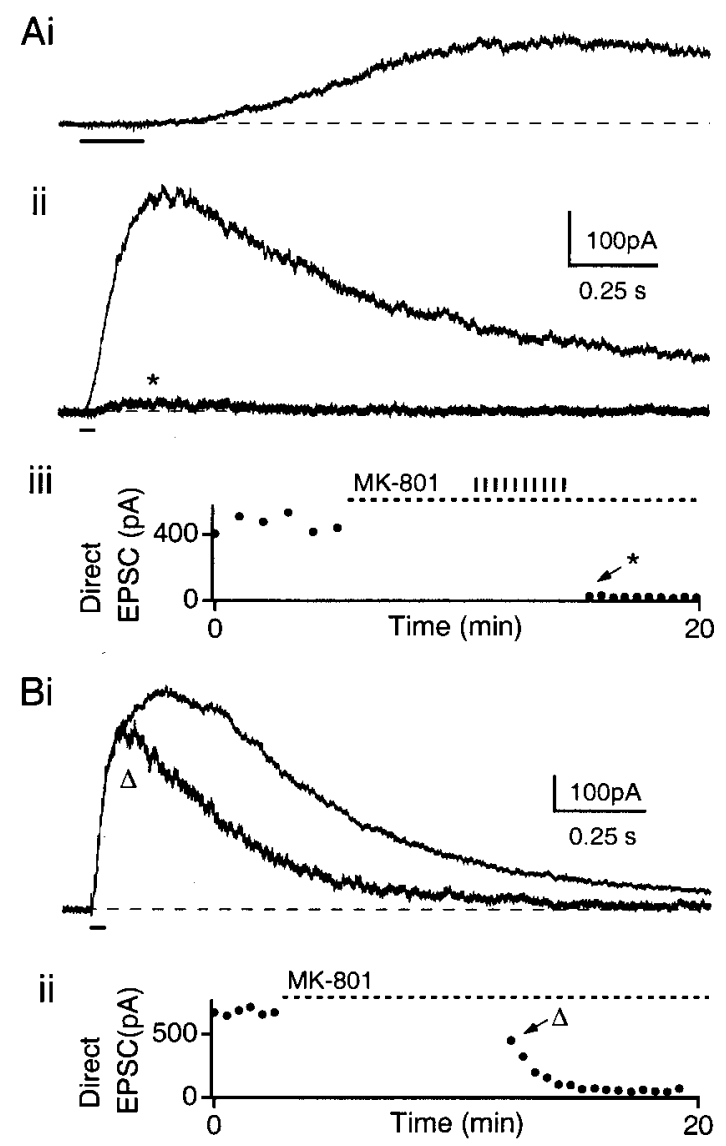

Figure 9. The indirect NMDAR-mediated EPSC is a consequence of glutamate spillover. $A i$, Indirect NMDAR EPSC evoked by 20 pulses at $100 \mathrm{~Hz}$. Aii, Direct NMDAR EPSCs evoked by five pulses at $100 \mathrm{~Hz}$ in control conditions (larger trace) and in MK-801 (smaller trace, *). Aiii, Peak direct NMDAR EPSCs as a function of time. After obtaining a stable recording (circles), $4 \mu \mathrm{M}$ MK-801 was added to the bath (horizontal dashed line). The indirect pathway was stimulated at the indicated times (vertical lines), and then the direct response was tested. The first time the direct response was tested in MK-801 $\left(^{*}\right)$, the EPSC was greatly reduced in size. In $B$, the experiment was repeated, except now the indirect pathway was not stimulated in the presence of MK-801. Bi, Direct NMDAR EPSCs evoked by five pulses at $100 \mathrm{~Hz}$ in control conditions (larger trace) and in MK-801 (smaller trace, $\Delta$ ). Bii, Peak direct NMDAR EPSCs as a function of time. The first time the direct response was tested in MK-801 $(\Delta)$, the EPSC was only slightly reduced in size. In all of the experiments, $10 \mu \mathrm{M}$ NBQX was present, and the holding potential was stepped from -70 to $+40 \mathrm{mV}$ to assess the NMDAR EPSC. Recordings in $A$ and $B$ are from different cells.

the direct pathway. For the cell in Figure $9 A$, the first direct response in MK-801 was $6 \%$ of the average direct response in control conditions (Fig. 9Aii, smaller trace, Aiii). For seven such experiments, the average amplitude of the first direct response in MK-801 was $33 \pm 9 \%$ of control. This large decrease suggested that the indirect response reflects glutamate spillover.

We also performed control experiments to verify that the decrease in the first direct response was attributable to glutamate spillover. These experiments were identical to those described above, except that the indirect pathway was not stimulated in the presence of MK-801. We found that the first direct response in MK-801 was slightly smaller than the average direct response in control conditions (Fig. 9Bi, Bii). For the cell in Figure 9B, the first direct response in MK-801 was $85 \%$ of control. For seven such experiments, the average first direct response in MK-801 
was $67 \pm 7 \%$ of control. Much of this decrease likely reflects the development of MK-801 open-channel block during the first direct response. In addition, MK-801 could block NMDARs opened by ambient extracellular glutamate during steps from -70 to $+40 \mathrm{mV}$. Finally, gradual rundown of the direct response during the $10 \mathrm{~min}$ for which it could not be tested may also contribute to this decrease.

Thus, the decrease in the first direct response in MK-801 after indirect pathway stimulation is primarily a reflection of glutamate spillover, because this decrease was much smaller when the indirect pathway was not stimulated $(33 \pm 9 \%$ with stimulation vs $67 \pm 7 \%$ without). These experiments thus establish that, at $24^{\circ} \mathrm{C}$, glutamate can diffuse from nearby synapses to activate NMDARs on a stellate cell.

\section{Prolonged AMPAR-mediated EPSC and glutamate spillover at $34^{\circ} \mathrm{C}$}

Previous studies have indicated that glutamate spillover can be much less prominent at more physiological temperatures (Asztely et al., 1997). We therefore tested whether the prolonged AMPAR-mediated EPSC and glutamate spillover that we have described at $24^{\circ} \mathrm{C}$ are also present at $34^{\circ} \mathrm{C}$.

We found that high-frequency, high-intensity direct pathway stimulation could generate a prolonged AMPAR-mediated EPSC at $34^{\circ} \mathrm{C}$ (Fig. $10 \mathrm{~A}$ ). A low-intensity stimulus train of five pulses at $100 \mathrm{~Hz}$ evoked rapidly decaying fast EPSCs (Fig. 10A, top). However, at a higher intensity, the same stimulus train produced fast EPSCs and a prolonged EPSC (Fig. 10 A, middle). This is shown by a scaled comparison of the two synaptic responses (Fig. $10 \mathrm{~A}$, bottom). We also found that indirect pathway stimulation could evoke indirect AMPAR-mediated EPSCs at $34^{\circ} \mathrm{C}$ (Fig. 10B). Direct (Fig. 10 Bi) and indirect (Fig. 10Bii) pathways were identified based on the presence of fast EPSCs. The indirect response was blocked by $10 \mu \mathrm{M}$ NBQX (Fig. 10Biii), suggesting that it was mediated by AMPARs. These findings suggest that stimulus trains can generate sustained glutamate signals and glutamate spillover at $34^{\circ} \mathrm{C}$.

We also used MK-801 to assess the ability of glutamate spillover to activate NMDARs at $34^{\circ} \mathrm{C}$ (Fig. 11). We found that the decrement of the first direct response in MK-801 depended on whether the indirect pathway was stimulated. In the examples shown, the first direct response in MK-801 was $18 \%$ of control when the indirect pathway was stimulated (Fig. 11A) and $74 \%$ of control when the indirect pathway was not stimulated (Fig. 11B). On average, the first direct response was $29 \pm 10 \%(n=4)$ of control with indirect pathway stimulation and $61 \pm 5 \%(n=5)$ of control without.

Together, these experiments establish that glutamate levels can be elevated for hundreds of milliseconds after a stimulus train at $34^{\circ} \mathrm{C}$. Moreover, glutamate can spill over from synapses and activate both AMPARs and NMDARs at nearby synapses even at this temperature.

\section{Effects of stimulus trains on stellate cell firing}

We next examined the effect of direct pathway stimulation on stellate cell firing at $24^{\circ} \mathrm{C}$. We first recorded from stellate cells using the cell-attached patch configuration, which does not alter the internal environment of the cells (Fig. 12A). For our experimental conditions $\left(\mathrm{GABA}_{\mathrm{A}}\right.$ receptors are blocked), these cells are spontaneously active at frequencies of $2-10 \mathrm{~Hz}$. For lowintensity stimulation, a single stimulus did not consistently evoke a response (Fig. 12Ai, left), as indicated by the representative
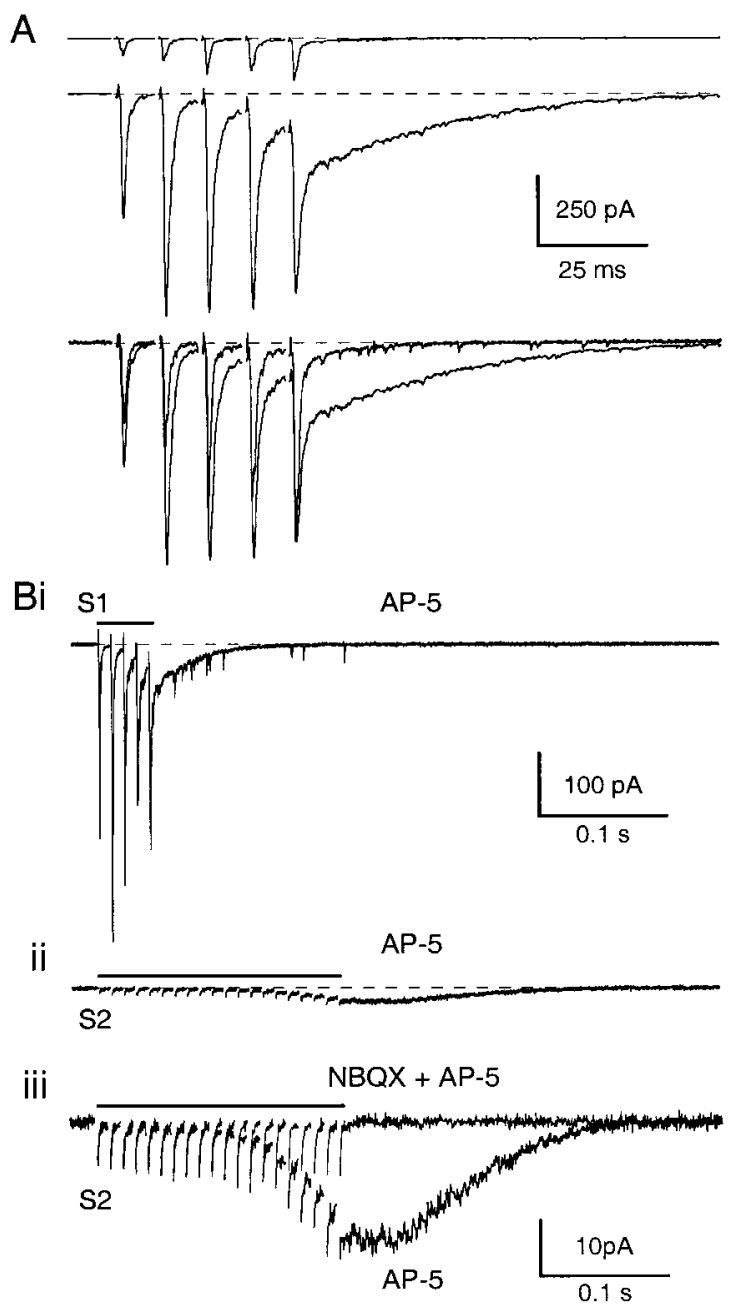

Figure 10. Slow direct and indirect AMPAR-mediated EPSCs are present at $34^{\circ} \mathrm{C}$. $A$, Direct AMPAR EPSCs evoked by five pulses at 100 $\mathrm{Hz}$ at low (top) or high (middle) stimulus intensity and a comparison of the responses scaled to the last peak (bottom). B, Direct AMPAR EPSCs evoked by five pulses at $100 \mathrm{~Hz}(\mathrm{~S} 1)(i)$ and indirect AMPAR EPSCs evoked by 20 pulses at $100 \mathrm{~Hz}$ (S2) (ii). Addition of $10 \mu \mathrm{M}$ NBQX blocked the indirect response (iii). Recordings were made at $-40 \mathrm{mV}$, and $50 \mu \mathrm{M}$ D-AP-5 was present for all experiments. Scale bar in $B i$ applies to $B i$ and Bii. Recordings in $A$ and $B$ are from different cells, and traces are averages of 5-20 trials.

trace and the raster plots for five trials. In contrast, a train of five stimuli at the same intensity increased stellate cell firing for $\sim 100$ msec (Fig. 12Ai, right). At a higher intensity, a single stimulus could reliably trigger an action potential (Fig. 12Aii, left). Furthermore, a stimulus train generated a more complex response (Fig. 12Aii, right) in which firing first briefly increased, then ceased for hundreds of milliseconds, and subsequently returned to baseline only after a rebound to relatively high firing rates. Similar effects on firing were observed in all seven cells tested. The long duration of the changes in firing after brief trains (Fig. $12 \mathrm{Ai}$, Aii, right) suggests a role for the prolonged EPSCs recorded in whole-cell voltage clamp. The response to high-intensity stimulus trains is particularly interesting in that activation of an excitatory input paradoxically inhibits stellate cell firing.

We further characterized the response of stellate cells to parallel fiber activation with whole-cell current-clamp recordings (Fig. 12B). The effects on stellate cell firing were similar to those 

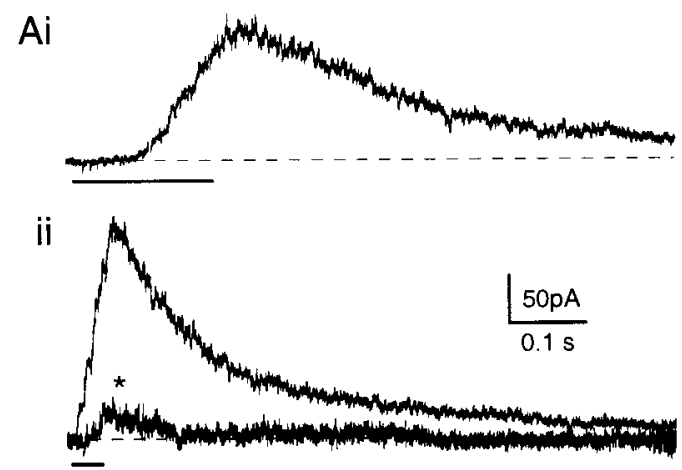

iii

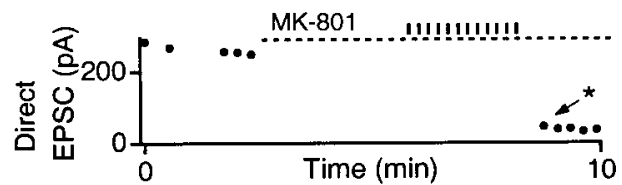

$\mathrm{Bi}$

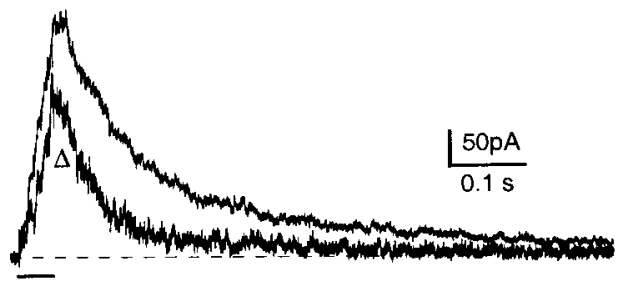

ii

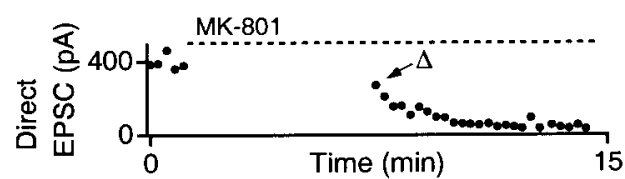

Figure 11. The indirect NMDAR-mediated EPSC at $34^{\circ} \mathrm{C}$ reflects glutamate spillover. These experiments were the same as those performed at $24^{\circ} \mathrm{C}$ (Fig. 9), except that now stimuli were separated by $15 \mathrm{sec}$, the MK-801 wash in time was 3 min, indirect pathway stimulation took place over a 3 min period, and the temperature was $34^{\circ} \mathrm{C}$. Recordings in $A$ and $B$ are from different cells.

observed in the cell-attached patch configuration. For lowintensity stimulation, a single stimulus did not trigger an action potential (Fig. 12Bi, left), but a train elevated firing rates for several hundred milliseconds (Fig. 12, Bi, right, C, left). At a higher intensity, a stimulus train evoked a prolonged depolarization to approximately $-30 \mathrm{mV}$ (Fig. 12, Bii, right, C, right). The stellate cell did not fire during this depolarization, likely as a consequence of $\mathrm{Na}^{+}$channel inactivation. Similar activity patterns were observed in all nine cells tested. The duration of this depolarization is similar to that of the prolonged EPSC recorded in whole-cell voltage clamp (compare Fig. 12C, right, with Fig. 1). These findings suggest that that the prolonged excitatory postsynaptic conductances described in this paper can interact with voltage-dependent conductances to have profound effects on stellate cell firing.

\section{DISCUSSION}

Our main finding is that brief stimulus trains can evoke prolonged synaptic responses mediated by AMPA and NMDA receptors that reflect the sustained presence of glutamate and glutamate spillover. These results also highlight the importance of glutamate transporters in regulating glutamate levels during trains and may have important physiological implications.
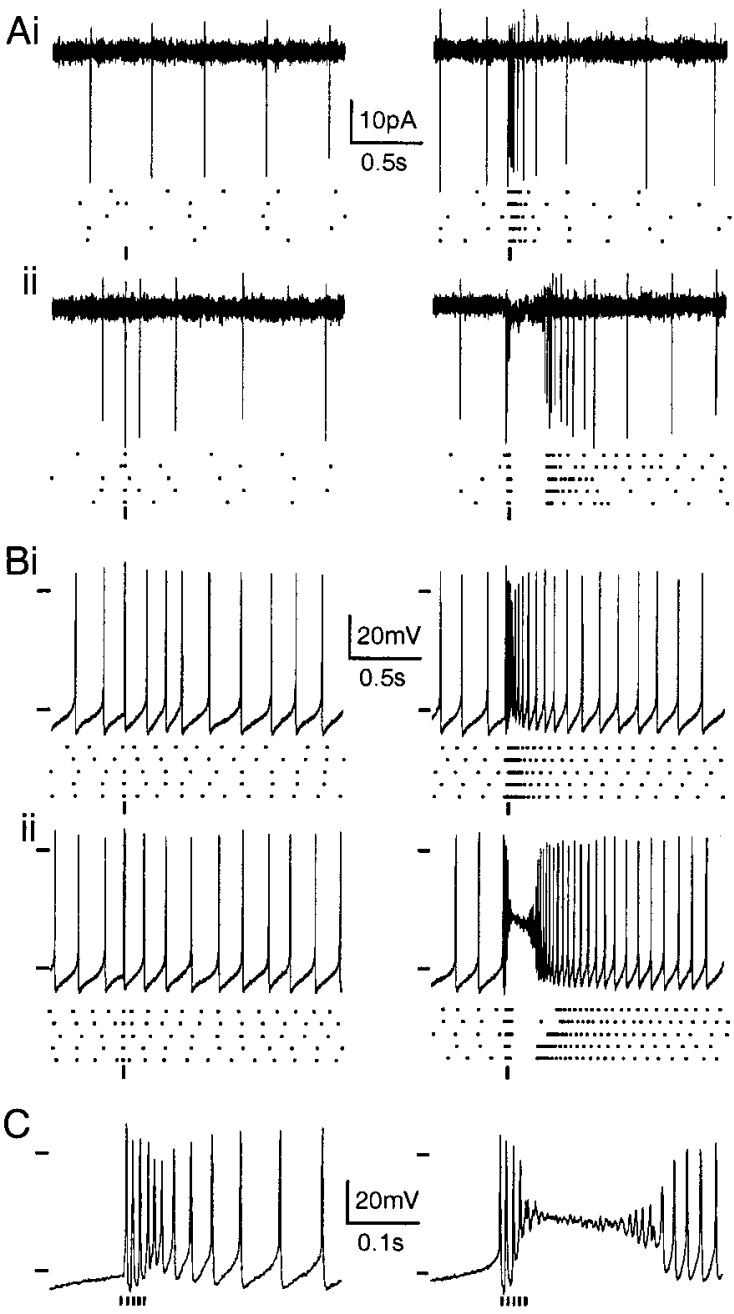

Figure 12. Response of stellate cells to parallel fiber stimulation. Cellattached patch recordings $(A)$ and whole-cell current-clamp recordings $(B)$ from stellate cells in response to one (left) or five (right) pulses at 100 $\mathrm{Hz}$ using low- $(i)$ or high- (ii) intensity stimulation. The high and low stimulus intensities differed by a factor of 2.5. Beneath each example in $A$ and $B$ is a raster plot showing spike timing for five consecutive trials. Below each raster plot is a marker indicating the time of stimulation. In $B$ and $C$, the horizontal markers correspond to -65 and $0 \mathrm{mV}$. In $C$, the responses to five pulses at $100 \mathrm{~Hz}$ are replotted on an expanded time scale to better show the initial response to low- $(C$, left, corresponding to $B i$, right $)$ and high- $(C$, right, corresponding to Bii, right $)$ intensity stimulation. Recordings in $A$ and $B$ are from different cells, and traces are single trial examples.

\section{EPSCs evoked by single stimuli and trains}

The EPSCs evoked by stimulation of a direct pathway with single stimuli and with brief trains are very different. This reflects both the contrasting glutamate signals produced by these two stimuli and the kinetics and glutamate affinities of the activated receptors.

A single stimulus evokes a prominent AMPAR-mediated EPSC (Barbour et al., 1994; Atluri and Regehr, 1998) and a much smaller NMDAR-mediated EPSC that is difficult to resolve (Glitsch and Marty, 1999). The brief EPSC mediated by AMPA receptors is a consequence of a short-lived glutamate transient that results primarily from phasic release of neurotransmitter (Atluri and Regehr, 1998; Chen and Regehr, 1999) and the rapid deactivation kinetics of the AMPA receptors (Barbour et al., 
1994). Furthermore, because the decay time of this rapid AMPAR-mediated EPSC is unaffected by either an increase in stimulus intensity or the inhibition of glutamate transporters, it is likely that this glutamate signal is relatively localized and independent of these transporters (Barbour et al., 1994). The small, long-lived response mediated by NMDA receptors is also consistent with a brief glutamate signal activating a small number of NMDA receptors with stereotypically slow kinetics (Lester et al., 1990; Edmonds et al., 1995).

Differences in responses evoked by trains and single stimuli are apparent for AMPAR- and NMDAR-mediated EPSCs, although these components are affected in different ways. For synaptic currents mediated by AMPA receptors, a slow component becomes prominent during trains that is not apparent in responses to single stimuli (Fig. 3). In contrast, for EPSCs mediated by NMDA receptors, the most obvious effect of stimulating with a train is to increase the peak response by 10 - to 20 -fold, and prolongation of the time course is less evident.

The properties of these EPSCs reflect very different glutamate signaling during trains. Presynaptic facilitation greatly increases the release of neurotransmitter during a train (Magleby, 1987; Zucker, 1989; Atluri and Regehr, 1996). Based on the amplitudes of EPSCs mediated by AMPA receptors, we estimate that, during a train of five pulses at $100 \mathrm{~Hz}$, facilitation results in a 10- to 20 -fold increase in glutamate release compared with a single stimulus. Trains also accentuate the delayed release of neurotransmitter, which further contributes to an increase in transmitter release (Atluri and Regehr, 1998). We propose that the resultant glutamate signal is long-lived and can spill over from the synaptic cleft.

Several aspects of the responses mediated by AMPA receptors suggest a sustained elevation of glutamate in responses to trains. First, the duration of the EPSC persists for longer than can be accounted for by AMPA receptor kinetics (Barbour et al., 1994; Edmonds et al., 1995). Second, the prolongation of the EPSC evoked by an increase in stimulus intensity (Fig. 3) indicates that the glutamate signal becomes larger and more effective at activating distant AMPA receptors when many presynaptic fibers are activated. Third, the prolongation of the EPSC by PDC (Fig. 5) indicates that glutamate transporters normally restrict the extent of the glutamate signal produced by a stimulus train.

The prominent NMDAR-mediated EPSC evoked by a stimulus train also reflects both the kinetics of NMDA receptors and the large glutamate signal generated by the train. The slow kinetics of the NMDA receptors (Lester et al., 1990; Edmonds et al., 1995) allow the stellate cell to integrate this glutamate signal over time. Because NMDA receptors have much slower off rates than AMPA receptors (Edmonds et al., 1995), it is difficult to resolve differences in the time course of evoked synaptic responses that are readily apparent with EPSCs mediated by AMPA receptors. Activation of extrasynaptic NMDA receptors may also contribute to the properties of the NMDAR-mediated EPSCs (Clark et al., 1997), although the distribution of NMDA receptors on the stellate cell is currently unknown.

\section{Glutamate spillover}

Our findings establish that glutamate spillover can activate both NMDA and AMPA receptors at the parallel fiber to stellate cell synapse. This was first suggested by prolongation of the AMPARmediated EPSC by an increase in stimulus intensity (Fig. 3), as described above. It was further indicated by the ability to evoke both NMDAR- and AMPAR-mediated EPSCs with indirect pathway stimulation (Fig. 8). Moreover, our experiments using MK-801 confirmed that glutamate spillover can activate NMDA receptors at this synapse (Fig. 9). From these experiments, we estimate that glutamate released during a stimulus train can diffuse for tens of micrometers to activate ionotropic glutamate receptors. It seems likely that this glutamate spillover contributes to both NMDAR- and AMPAR-mediated EPSCs evoked by direct pathway stimulation. Finally, our experiments show that these phenomena occur at both 24 and $34^{\circ} \mathrm{C}$.

The AMPAR-mediated EPSCs evoked by direct- and indirectpathway stimulus trains indicate that glutamate spillover can activate AMPA receptors. This result was surprising, because these receptors are thought to mediate only fast synaptic responses to brief glutamate signals at most synapses. However, previous studies indicate that, at calyceal and glomerular synapses, glutamate spillover can activate AMPA receptors (Rossi et al., 1995; Otis and Trussell, 1996; Otis et al., 1996; Silver et al., 1996; Kinney et al., 1997; Slater et al., 1997; Overstreet et al., 1999). At these synapses, glutamate is released from multiple sites into a confined space, which can lead to an extended glutamate signal and glutamate spillover. However, this specialized geometry is atypical, and the en passant parallel fiber to stellate cell synapse is more characteristic of central synapses. Parallel fibers synapse onto the dendritic shafts of stellate cells at which bergmann glia processes are sparse (Palay and Chan-Palay, 1974) and glutamate transporter density is low (Chaudhry et al., 1995). For a single stimulus, these factors allow for the small amount of released glutamate to diffuse into the local extrasynaptic space, resulting in a brief glutamate signal (Barbour et al., 1994). However, for a stimulus train, these same factors permit the large amount of released glutamate to spill over to nearby synapses. Thus, as at glomerular and calyceal synapses, the structure of the parallel fiber to stellate cell synapse also appears to permit AMPA receptor activation by glutamate spillover in response to a stimulus train.

\section{Significance}

Our results may have implications for circuit properties and plasticities in the cerebellum. Granule cell firing depolarizes both stellate and Purkinje cells, thereby promoting firing in these two cell types. As synaptic activation becomes sufficiently large to fire stellate cells, they will in turn inhibit Purkinje cells and thereby limit the ability of granule cells to promote Purkinje cell firing. However, more powerful synaptic activation may prolong the presence of glutamate at the stellate cell synapse (Fig. 12). The resulting depolarization could be sufficiently large to prevent stellate cell firing by inactivating $\mathrm{Na}^{+}$channels (Fig. 12C, right), thereby reducing inhibition and increasing the efficacy of parallel fiber inputs to Purkinje cells.

The prolonged EPSCs evoked by high-frequency stimulus trains only became prominent when large populations of parallel fibers were activated. This suggests that high-frequency firing of individual granule cells may generate neither an extended glutamate signal nor spillover. Nevertheless, several points suggest that our results have broad implications for the behavior of many types of synapses. First, populations of excitatory neurons, including cerebellar granule cells, often display high-frequency firing in vivo, particularly during behavioral tasks (Hartmann and Bower, 1998). Second, epilepsy can result in similar high-frequency synchronous firing in neurons. Third, many experiments use similar stimulation protocols to study synaptic transmission and plastic- 
ity. Glutamate spillover and prolonged EPSCs may become prominent in each of these three cases.

\section{REFERENCES}

Asztely F, Erdemli G, Kullmann DM (1997) Extrasynaptic glutamate spillover in the hippocampus: dependence on temperature and the role of active glutamate uptake. Neuron 18:281-293.

Atluri PP, Regehr WG (1996) Determinants of the time course of facilitation at the granule cell to Purkinje cell synapse. J Neurosci 16:5661-5671.

Atluri PP, Regehr WG (1998) Delayed release of neurotransmission from cerebellar granule cells. J Neurosci 18:8214-8227.

Bahn S, Volk B, Wisden W (1994) Kainate receptor gene expression in the developing rat brain. J Neurosci 14:5525-5547.

Barbour B, Hausser M (1997) Intersynaptic diffusion of neurotransmitter. Trends Neurosci 20:377-384.

Barbour B, Keller BU, Llano I, Marty A (1994) Prolonged presence of glutamate during excitatory synaptic transmission to cerebellar Purkinje cells. Neuron 12:1331-1343.

Baude A, Nusser Z, Roberts JD, Mulvihill E, McIlhinney RA, Somogyi $P$ (1993) The metabotropic glutamate receptor (mGluR1 alpha) is concentrated at perisynaptic membrane of neuronal subpopulations as detected by immunogold reaction. Neuron 11:771-787.

Bergles DE, Diamond JS, Jahr CE (1999) Clearance of glutamate inside the synapse and beyond. Curr Opin Neurobiol 9:293-298.

Castillo PE, Malenka RC, Nicoll RA (1997) Kainate receptors mediate a slow postsynaptic current in hippocampal CA3 neurons. Nature 388:182-186.

Chaudhry FA, Lehre KP, van Lookeren Campagne M, Ottersen OP, Danbolt NC, Storm-Mathisen J (1995) Glutamate transporters in glial plasma membranes: highly differentiated localizations revealed by quantitative ultrastructural immunocytochemistry. Neuron 15:711-720.

Chen C, Regehr WG (1999) Contributions of residual calcium to fast synaptic transmission. J Neurosci 19:6257-6266.

Clark BA, Farrant M, Cull-Candy SG (1997) A direct comparison of the single-channel properties of synaptic and extrasynaptic NMDA receptors. J Neurosci 17:107-116.

Clements JD (1996) Transmitter timecourse in the synaptic cleft: its role in central synaptic function. Trends Neurosci 19:163-171.

Clements JD, Lester RA, Tong G, Jahr CE, Westbrook GL (1992) The time course of glutamate in the synaptic cleft. Science 258:1498-1501.

Cull-Candy SG, Brickley SG, Misra C, Feldmeyer D, Momiyama A, Farrant M (1998) NMDA receptor diversity in the cerebellum: identification of subunits contributing to functional receptors. Neuropharmacology 37:1369-1380.

Diamond JS, Jahr CE (1995) Asynchronous release of synaptic vesicles determines the time course of the AMPA receptor-mediated EPSC. Neuron 15:1097-1107.

Diamond JS, Jahr CE (1997) Transporters buffer synaptically released glutamate on a submillisecond time scale. J Neurosci 17:4672-4687.

Dzubay JA, Jahr CE (1999) The concentration of synaptically released glutamate outside of the climbing fiber-Purkinje cell synaptic cleft. J Neurosci 19:5265-5274.

Edmonds B, Gibb AJ, Colquhoun D (1995) Mechanisms of activation of glutamate receptors and the time course of excitatory synaptic currents. Annu Rev Physiol 495-519.

Frerking M, Wilson M (1996) Saturation of postsynaptic receptors at central synapses? Curr Opin Neurobiol 6:395-403.

Glitsch M, Marty A (1999) Presynaptic effects of NMDA in cerebellar Purkinje cells and interneurons. J Neurosci 19:511-519.

Hartmann MJ, Bower JM (1998) Oscillatory activity in the cerebellar hemispheres of unrestrained rats. J Neurophysiol 80:1598-1604.

Herrington J, Bookman RJ (1995) Pulse Control V4.5: IGOR XOPs for Patch Clamp Data Acquisition. Miami: University of Miami.

Hessler NA, Shirke AM, Malinow R (1993) The probability of transmitter release at a mammalian central synapse. Nature 366:569-572.

Hestrin S (1992) Activation and desensitization of glutamate-activated channels mediating fast excitatory synaptic currents in the visual cortex. Neuron 9:991-999.

Hestrin S (1993) Different glutamate receptor channels mediate fast excitatory synaptic currents in inhibitory and excitatory cortical neurons. Neuron 11:1083-1091.

Hestrin S, Nicoll RA, Perkel DJ, Sah P (1990a) Analysis of excitatory synaptic action in pyramidal cells using whole-cell recording from rat hippocampal slices. J Physiol (Lond) 422:203-225.
Hestrin S, Sah P, Nicoll RA (1990b) Mechanisms generating the time course of dual component excitatory synaptic currents recorded in hippocampal slices. Neuron 5:247-253.

Huettner JE, Bean BP (1988) Block of $N$-methyl-D-aspartate-activated current by the anticonvulsant MK-801: selective binding to open channels. Proc Natl Acad Sci USA 85:1307-1311.

Isaacson JS, Nicoll RA (1993) The uptake inhibitor L-trans-PDC enhances responses to glutamate but fails to alter the kinetics of excitatory synaptic currents in the hippocampus. J Neurophysiol 70:2187-2191.

Jahr CE (1992) High probability opening of NMDA receptor channels by L-glutamate. Science 255:470-472.

Jonas P, Spruston N (1994) Mechanisms shaping glutamate-mediated excitatory postsynaptic currents in the CNS. Curr Opin Neurobiol 4:366-372.

Kinney GA, Overstreet LS, Slater NT (1997) Prolonged physiological entrapment of glutamate in the synaptic cleft of cerebellar unipolar brush cells. J Neurophysiol 78:1320-1333.

Kullmann D, Erdemli G, Asztely F (1996) LTP of AMPA and NMDA receptor-mediated signals: evidence for presynaptic expression and extrasynaptic glutamate spill-over. Neuron 17:461-474.

Kullmann DM, Asztely F (1998) Extrasynaptic glutamate spillover in the hippocampus: evidence and implications. Trends Neurosci 21:8-14.

Lehre KP, Levy LM, Ottersen OP, Storm-Mathisen J, Danbolt NC (1995) Differential expression of two glial glutamate transporters in the rat brain: quantitative and immunocytochemical observations. J Neurosci 15:1835-1853.

Lester RA, Clements JD, Westbrook GL, Jahr CE (1990) Channel kinetics determine the time course of NMDA receptor-mediated synaptic currents. Nature 346:565-567.

Llano I, Marty A, Armstrong CM, Konnerth A (1991) Synaptic- and agonist-induced excitatory currents of Purkinje cells in rat cerebellar slices. J Physiol (Lond) 434:183-213.

Magleby KL (1987) Short-term changes in synaptic efficacy. In: Synaptic function (Edelman GM, Gall WE, Cowan WM, eds), pp 21-56. New York: Wiley.

Mennerick S, Zorumski CF (1995) Presynaptic influence on the time course of fast excitatory synaptic currents in cultured hippocampal cells. J Neurosci 15:3178-3192.

Min MY, Rusakov DA, Kullmann DM (1998) Activation of AMPA, kainate, and metabotropic receptors at hippocampal mossy fiber synapses: role of glutamate diffusion. Neuron 21:561-570.

Monyer H, Burnashev N, Laurie DJ, Sakmann B, Seeburg PH (1994) Developmental and regional expression in the rat brain and functional properties of four NMDA receptors. Neuron 12:529-540.

Otis TS, Trussell LO (1996) Inhibition of transmitter release shortens the duration of the excitatory synaptic current at a calyceal synapse. J Neurophysiol 76:3584-3588.

Otis TS, Wu YC, Trussell LO (1996) Delayed clearance of transmitter and the role of glutamate transporters at synapses with multiple release sites. J Neurosci 16:1634-1644.

Overstreet LS, Kinney GA, Liu YB, Billups D, Slater NT (1999) Glutamate transporters contribute to the time course of synaptic transmission in cerebellar granule cells. J Neurosci 19:9663-9673.

Palay SL, Chan-Palay V (1974) Cerebellar cortex. New York: Springer.

Patneau DK, Mayer ML (1990) Structure-activity relationships for amino acid transmitter candidates acting at $N$-methyl-D-aspartate and quisqualate receptors. J Neurosci 10:2385-2399.

Patneau DK, Vyklicky Jr L, Mayer ML (1993) Hippocampal neurons exhibit cyclothiazide-sensitive rapidly desensitizing responses to kainate. J Neurosci 13:3496-3509.

Pearce RA (1993) Physiological evidence for two distinct GABAA responses in rat hippocampus. Neuron 10:189-200.

Regehr WG, Atluri PP (1995) Calcium transients in cerebellar granule cell presynaptic terminals. Biophys J 68:2156-2170.

Regehr WG, Tank DW (1991) Selective fura-2 loading of presynaptic terminals and nerve cell processes by local perfusion in mammalian brain slice. J Neurosci Methods 37:111-119.

Rosenmund C, Clements JD, Westbrook GL (1993) Nonuniform probability of glutamate release at a hippocampal synapse. Science 262:754-757.

Rossi DJ, Alford S, Mugnaini E, Slater NT (1995) Properties of transmission at a giant glutamatergic synapse in cerebellum: the mossy fiber-unipolar brush cell synapse. J Neurophysiol 74:24-42.

Rothstein JD, Martin L, Levey AI, Dykes-Hoberg M, Jin L, Wu D, Nash 
N, Kuncl RW (1994) Localization of neuronal and glial glutamate transporters. Neuron 13:713-725.

Sarantis M, Ballerini L, Miller B, Silver RA, Edwards M, Attwell D (1993) Glutamate uptake from the synaptic cleft does not shape the decay of the non-NMDA component of the synaptic current. Neuron 11:541-549.

Scanziani M, Salin PA, Vogt KE, Malenka RC, Nicoll RA (1997) Usedependent increases in glutamate concentration activate presynaptic metabotropic glutamate receptors. Nature 385:630-634.

Silver RA, Cull-Candy SG, Takahashi T (1996) Non-NMDA glutamate receptor occupancy and open probability at a rat cerebellar synapse with single and multiple release sites. J Physiol (Lond) 494:231-250.

Slater NT, Rossi DJ, Kinney GA (1997) Physiology of transmission at a giant glutamatergic synapse in cerebellum. Prog Brain Res 114:151-163.
Spruston N, Jaffe DB, Williams SH, Johnston D (1993) Voltage- and space-clamp errors associated with the measurement of electrotonically remote synaptic events. J Neurophysiol 70:781-802.

Trussell LO, Zhang S, Raman IM (1993) Desensitization of AMPA receptors upon multiquantal neurotransmitter release. Neuron 10:1185-1196.

Vignes M, Collingridge GL (1997) The synaptic activation of kainate receptors. Nature 388:179-182.

Vogt KE, Nicoll RA (1999) Glutamate and gamma-aminobutyric acid mediate a heterosynaptic depression at mossy fiber synapses in the hippocampus. Proc Natl Acad Sci USA 96:1118-1122.

Zucker RS (1989) Short-term synaptic plasticity. Annu Rev Neurosci 12:13-31.

Zucker RS (1999) Calcium- and activity-dependent synaptic plasticity. Curr Opin Neurobiol 9:305-313. 